\title{
PENGARUH DEPOSISI PARTIKEL-PARTIKEL ION NEGATIF PADA KONDISI ATMOSFER TERHADAP KAIN POLIESTER GREY
}

\author{
THE INFLUENCE OF ATMOSPHERIC NEGATIVE ION PARTICLES \\ DEPOSITION ON POLYESTER GREY FABRIC
}

\author{
Zaenul Muhlisin ${ }^{1,2}$, Dhyan Prastiwi ${ }^{1,2}$, Fajar Ariyanto ${ }^{1,2}$, Achmad Sjaifudin T. ${ }^{3}$, Pandji Triadyaksa ${ }^{1,2}$ \\ ${ }^{1}$ Departemen Fisika, Fakultas Sains dan Matematika, Universitas Diponegoro, Semarang, 50275, Indonesia \\ E-mail: fisika@undip.com \\ departemen@fisika.undip.ac.id \\ ${ }^{2}$ Center for Plasma Research, Universitas Diponegoro, Semarang, Indonesia \\ E-mail: ariantofajar@gmail.com \\ ${ }^{3}$ Balai Besar Tekstil \\ E-mail:iputbbt@gmail.com
}

Tanggal diterima: 28 Juni 2018, direvisi: 14 Desember 2018, disetujui terbit: 17 Desember 2018

\begin{abstract}
ABSTRAK
Penelitian ini bertujuan untuk menganalisa daerah kerja plasma korona pada kondisi atmosfer dalam pembangkitan partikel - partikel ion negatif guna memperoleh nilai mobilitas ion rerata pembawa muatannya. Karakteristik ini dilakukan dengan menggunakan sampel kain poliester grey dan tanpa kain sebagai pembanding. Lebih lanjut, penelitian ini juga menganalisa karakteristik kain poliester grey setelah diiradiasi dengan plasma korona negatif. Penelitian ini menggunakan reaktor plasma berarus negatif yang tersusun atas elektroda multi titik dan elektroda bidang. Elektroda titik berdiameter 0,5 mm sebanyak 100 titik dengan jarak tiap titik 1,3 cm dan elektroda bidang berukuran 25 x $25 \mathrm{~cm}^{2}$. Sampel kain tenun berbahan Poliester grey berukuran $10 \times 10 \mathrm{~cm}^{2}$ diiradasi pada elektroda bidang. Daerah kerja plasma korona negatif pada kondisi atmosfer dianalisa melalui karakteristik arus-tegangan pada variasi jarak antara elektroda mulai 0,9 cm hingga 3,6 cm dengan beda potensial pembangkitan plasma antara $0-4 \mathrm{kV}$. Hasil penelitian menunjukkan bahwa kuat arus listik meningkat bersamaan dengan penambahan beda potensial serta penempatan kain poliester grey pada elektroda bidang cenderung menurunkan arus listrik dari plasma korona negatif. Nilai mobilitas ion yang dihasilkan menunjukkan semakin kecilnya mobilitas ion yang dihasilkan saat jarak antar elektroda (d) semakin jauh. Hasil pengujian tetes cairan pada kain poliester grey setelah iradiasi menunjukkan adanya perubahan sifat fisis kain. Pada jarak antar elektroda multi titik dan bidang sebesar 2,1 cm dengan lama peradiasian 35 menit, hasil dominan kecepatan waktu serap rerata kain diperoleh sebesar 1,06 detik dimana sebelum iradiasi melebihi 17 detik.
\end{abstract}

Kata kunci: Plasma korona, multi titik-bidang, mobilitas ion, kain poliester, perlakuan tekstil

\section{ABSTRACT}

This study aims to analyze the working area of corona plasma in atmospheric conditions in generating negative ion particles to obtain its average carrier ion mobility value. This characteristic is conducted by using polyester geay fabric sample and without using the sample as a comparison. Furthermore, this study also analyzed the characteristics of polyester grey fabric after negative corona plasma irradiation. This study uses a negative current plasma reactor which is composed of a multi-point electrode and a plate electrode. The multi-point electrode consisted of $0.5 \mathrm{~mm}$ diameter of 100 points with a distance of each point of $1.3 \mathrm{~cm}$ and the plate electrode has a dimension of $25 \times 25 \mathrm{~cm}^{2}$. Woven fabric samples made from Polyester gray with a dimension of $10 \times 10 \mathrm{~cm}^{2}$ were irradiated on the plate electrode. The working area of negative corona plasma in atmospheric conditions is analyzed through the characteristics of voltage-current variations in the distance between electrodes from $0.9 \mathrm{~cm}$ to $3.6 \mathrm{~cm}$ with a potential difference in plasma generation between $0-4 \mathrm{kV}$. The results showed that the strength of electric current increased together with the addition of potential differences and the placement of polyester grey fabric on the plate electrode tending to reduce the electric current from the negative corona plasma. The resulting ion mobility value shows the smaller mobility of ions produced when the distance between electrodes (d) gets farther away. The results of liquid drop testing on polyester grey fabric after irradiation showed a change in the physical properties of the fabric. At a distance between electrodes of $2.1 \mathrm{~cm}$ with a duration of 35 minutes, the dominant results of the average absorbency time of the fabric were obtained by 1.06 seconds which before the irradiation exceeded 17 seconds.

Keywords: Plasma corona, multi point-field, ion mobility, poliester fabric,textile treatment. 


\section{PENDAHULUAN}

Dalam industri tekstil proses penyempurnaan kain selalu dilakukan untuk memperbaiki kekurangan dari sifat-sifat pada kain. Banyak cara penyempurnaan pada kain, baik secara fisik maupun kimia. Hanya saja dalam prosesnya diperlukan banyak energi terutama pada pengolahan basah kain. Pengolahan basah kain, seperti gosok, desizing, pemutihan, pencelupan / percetakan, dan finishing, mengkonsumsi sejumlah besar air, menghasilkan polusi melalui limbah, dan mengkonsumsi sejumlah besar energi. ${ }^{1}$ Penggunaan radiasi untuk material berserat menunjukkan potensi yang menjanjikan karena mampu meningkatkan berbagai sifat fungsional pada bahan tekstil yang mendapat perlakuan radiasi plasma, ${ }^{2}$ salah satunya yaitu meningkatkan sifat hidrofilik pada kain tersebut, sehingga kain memiliki daya serap yang tinggi.

Plasma adalah gas terionisasi, keadaan materi keempat yang berbeda. "Terionisasi” berarti bahwa paling tidak satu elektron tidak terikat ke atom atau molekul, konversi atom atau molekul menjadi ion - ion bermuatan positif. ${ }^{3}$ Plasma yang terbentuk dalam lucutan listrik dikenal dengan lucutan pijar korona. ${ }^{4}$ Plasma lucutan pijar korona yang dimanfaatkan dalam industri tekstil diharapkan menghasilkan medan listrik yang mendekati seragam pada target, maka digunakan lucutan korona dengan konfigurasi titik bidang untuk memudahkan aliran elektrohidrodinamik (EHD) menuju target, dalam hal ini adalah kain poliester grey. ${ }^{5}$ Lucutan korona telah terbukti merupakan suatu metode yang berguna untuk meningkatkan sifat hidrofilik permukaan polimer, terutama dalam meningkatkan kekuatan material komposit. Weilin Xu dan Xin Liu pada 2003 melaporkan penggunaan lucutan korona untuk modifikasi permukaan poliester. ${ }^{6}$

Pada lucutan korona, terdapat aliran ion seragam yang mengalir ke elektroda bidang. Daerah ini disebut daerah arus unipolar. ${ }^{3}$ Arus dapat berupa ion-ion negatif maupun positif sesuai dengan elektroda pasif diperlakukan. Bila elektoda pasif diperlakukan sebagai anoda maka terjadi arus ionion negatif yang akan menumbuknya. Pada kondisi atmosfer partikel-partikel ion negatif didominasi oleh partikel $\mathrm{O}_{2}{ }^{-}$dan $\mathrm{N}_{2}{ }^{-}$, selain elektron. ${ }^{4}$

Perkembangan terkini dalam pemanfaatan plasma untuk bahan tekstil memiliki potensi besar sebagai alternatif teknologi untuk pengolahan tekstil, karena hemat biaya, hemat air, dan ramah lingkungan. Dalam penelitian ini dikaji perubahan sifat-sifat fisik kain poliester akibat perlakuan plasma, sehingga sifat hidrofilik pada kain poliester meningkat. Jenis plasma yang digunakan dalam penelitian ini adalah plasma pijar korona berarus negatif dengan konfigurasi elektroda multi titikbidang. Langkah-langkah yang dilakukan yaitu mengkarakterisasi reaktor plasma dan menentukan mobilitas rerata pembawa muatan dengan tujuan untuk menentukan daerah kerja reaktor yang paling optimum, kemudian melakukan perlakuan pada kain dan menguji hasilnya dengan uji tetes cairan.

\section{METODE}

\section{Karakterisasi Arus dan Tegangan}

Penelitian diawali dengan melakukan karakteristik arus listrik sebagai fungsi tegangan pada reaktor. Karakterisasi dilakukan pada beberapa variasi jarak antara dua elektroda. Sedangkan pada proses iradiasi, sampel kain poliester ditempatkan pada permukaan elektroda bidang. Skema peralatan penelitian dapat dilihat pada gambar 1.

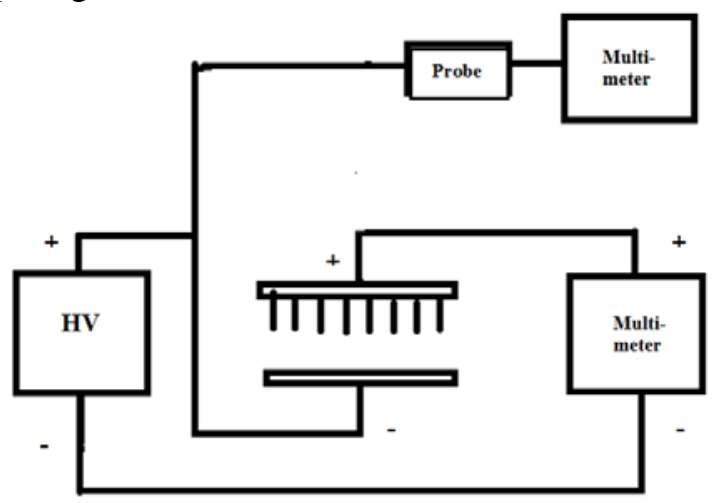

Gambar 1. Rangkaian penelitian pembangkit ionion negatif kondisi atmosfer

Untuk menghasilkan plasma berarus negatif, elektroda titik diberi polaritas negatif dan elektroda pasif diberi polaritas postif. Arus listrik di rangkaian diukur dengan menggunakan multimeter (WINNER, model YX-360TREB, tegangan $220 \mathrm{~V}$, frekuensi $50 / 60 \mathrm{~Hz}$, Buatan China), sedangkan nilai Tegangan yang dihasilkan oleh catu daya DC tegangan tinggi (HV) diukur dengan menggunakan multimeter (SANWA, tipe CD771) terhubung ke probe tegangan tinggi (DC max Voltage DC $40 \mathrm{kV}$, AC 28 kV model no: PD-28, Serial no: 01605733). Parameter arus, tegangan dan jarak antar elektroda pada penelitian ini divariasikan. Variasi jarak elektroda antara elektroda adalah $0,9 \mathrm{~cm} ; 1,2 \mathrm{~cm}$; $1,5 \mathrm{~cm} ; 1,8 \mathrm{~cm} ; 2,1 \mathrm{~cm} ; 2,4 \mathrm{~cm} ; 2,7 \mathrm{~cm} ; 3 \mathrm{~cm} ; 3,3$ cm dan 3,6 cm, sedangkan jarak elektroda untuk iradiasi kain adalah 1,2 cm; 1,5 cm; 1,8 cm; 2,1 cm; dan 2,4 cm. Variasi waktu deposisi partikel bermuatan negatif terhadap kain yaitu, 10 menit, 15 menit, 20 menit, 25 menit, 30 menit, dan 35 menit. Penilaian perubahan sifat fisik-kimia pada kain menggunakan uji tetes cairan dengan uji tunda 24 jam.

\section{Mobilitas Ion}

Mobilitas ion adalah kecepatan yang diperoleh suatu ion yang bergerak dalam ruang elektroda dalam setiap satuan medan listrik. 
Mobilitas pembawa muatan $(\mu)$ dipengaruhi oleh karakteristik arus dan tegangan (I-V), karateristik arus-tegangan dilakukan dengan pendekatan perumusan Robinson secara teoritik. ${ }^{5}$

Perhitungan nilai mobilitas pembawa muatan pada plasma pijar korona tanpa sampel kain dan dengan sampel kain poliester grey menggunakan persamaan arus saturasi unipolar, sesuai persamaan (1).

$$
I_{s}=\frac{2 \mu \varepsilon_{g} V^{2} n_{g}}{d}
$$

sehingga didapatkan persamaan untuk mobilitas ion yang dinyatakan pada persamaan (2)

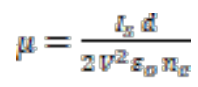

dengan, $\mu$ adalah mobilitas ion unipolar $\left(\mathrm{cm}^{2} / \mathrm{V} . \mathrm{s}\right)$, $\varepsilon_{0}$ adalah permitivitas udara $(\mathrm{F} / \mathrm{m}), \mathrm{d}$ adalah jarak antar elektroda $(\mathrm{cm}), n_{\varepsilon}$ adalah jumlah titik pada elektroda, $\mathrm{V}$ adalah tegangan $(\mathrm{kV})$, dan $I_{\sigma}$ adalah arus $(\mathrm{mA})^{3}$

\section{HASIL DAN PEMBAHASAN}

Karakterisasi arus (I) dan tegangan (V) pada reaktor plasma tanpa sampel ataupun dengan sampel kain bertujuan untuk mengetahui keadaan lucutan plasma korona yang stabil untuk peradiasian kain. Karakteristik arus (I) dan tegangan $(V)$ didapatkan dengan cara menyuplai tegangan tinggi secara perlahan, hingga dapat diketahui lucutan yang stabil dengan arus yang signifikan. Ketika sumber tegangan dinyalakan maka akan terjadi beda potensial antar kutub sehingga menghasilkan aliran arus dari kutub negatif (-) menuju kutub positif $(+)$. Kemudian tegangan akan dinaikkan perlahan sehingga aliran arus akan menuju elektroda dan terjadi lucutan di antar elektroda titik-bidang. Elektron dari katoda akan bergerak menuju anoda dan elektron akan saling bertumbukan sehingga menghasilkan medan listrik yang tidak seragam yang kuat antara elektroda, kemudian terjadi pergerakan elektron di antar elektroda titik-bidang. Selama perjalanannya elektron akan menumbuk molekul-molekul/atomatom gas di antara elektroda sehingga terjadi proses ionisasi yaitu dimana elektron akan terlepas dari kulitnya karena adanya tambahan energi. Proses ionisasi pertama diyakini berasal dari tumbukan antara gas dengan sinar kosmis yang menghasilkan elektron. Elektron ini akan dipercepat oleh beda potensial antar elektroda dan selama perjalanannya elektron akan menumbuk dan mengionisasi atom atau molekul gas lain, demikian seterusnya. Proses tumbukan secara terus-menerus akan menghasilkan guguran elektronik dan mengakibatkan ionisasi berantai. Ionisasi berantai akan mengalami ketidakstabilan dimana energi mengalami penurunan dan deeksitasi. Ketika energi mengalami deeksitasi maka akan terjadi proses rekombinasi dengan cara pengikatan elektron oleh ion dan pengikatan antar atom menjadi molekul sehingga menjadi spesies netral atau ion negatif yang disertai pemancaran foton. ${ }^{3}$ Proses ionisasi dan rekombinasi ini mengakibatkan proses lucutan di antara elektroda titik-bidang.

Proses terjadinya lucutan pijar korona dalam medan listrik diawali dengan lucutan townsend kemudian diikuti oleh lucutan pijar (glow discharge) atau korona (corona discharge) dan berakhir dengan lucutan arc. ${ }^{7}$ Pada lucutan pijar korona ionisasi terjadi di sekitar elektroda titik, karena pengaruh medan listrik ion-ion hasil ionisasi akan mengalir atau bergerak menuju katoda melalui daerah aliran (drift region). Aliran ion-ion ini akan menimbulkan arus ion yaitu disebut arus saturasi unipolar. Plasma lucutan pijar korona negatif dapat dibentuk dengan memberi polaritas negatif pada elektroda titik, sehingga ion yang mengalir melalui daerah aliran merupakan ion-ion yang bermuatan negatif. Ion-ion bermuatan negatif terbentuk karena di dalam udara terdapat molekul elektronegatif $\left(\mathrm{O}_{2}\right)$ yang mempunyai sifat sangat mudah menangkap electron. ${ }^{3}$ Pada penelitian karakterisasi reaktor plasma didapatkan nilai arus pada tegangan tertentu seperti ditunjukkan pada Gambar 2.

Pada Gambar 2 terlihat grafik karakterisasi arus $(I)$ sebagai fungsi tegangan $(V)$ pada jarak $(d)$ tertentu baik tanpa sampel maupun dengan sampel kain poliester grey. Dari grafik dapat diketahui bahwa semakin besar jarak elektroda maka semakin besar juga tegangan yang dibutuhkan untuk menghasilkan arus deposisi partikel ion negatif. Bila beda potensial yang diberikan semakin ditingkatkan maka aruspun semakian meningkat. Hal ini sesuai dengan persamaan arus saturasi unipolar yaitu arus berbanding terbalik dengan jarak elektroda. Dapat terlihat dari hasil karakterisasi, semakin tinggi jarak elektroda, maka semakin besar tegangan yang dibutuhkan sehingga terjadi kerenggangan pada kurva karakterisasi I-V.

Perbedaan yang terjadi pada Gambar 2 (a) dan Gambar 2 (b) adalah besarnya tegangan yang dibutuhkan untuk menghasilkan arus, pada karakterisasi dengan sampel tegangan yang dibutuhkan lebih rendah dibandingkan dengan karakterisasi tanpa sampel. Hal ini dikarenakan saat elektroda disisipi bahan dielektrik (kain poliester grey) dan diberikan medan listrik, maka akan terbentuk dipol-dipol listrik pada bahan dielektrik akibat adanya medan listik. Dipol-dipol listrik yang terbentuk akan mengganggu medan listrik diantara elektroda, sehingga arus lebih cepat dihasilkan dibandingkan dengan yang tanpa sampel. ${ }^{8}$ 


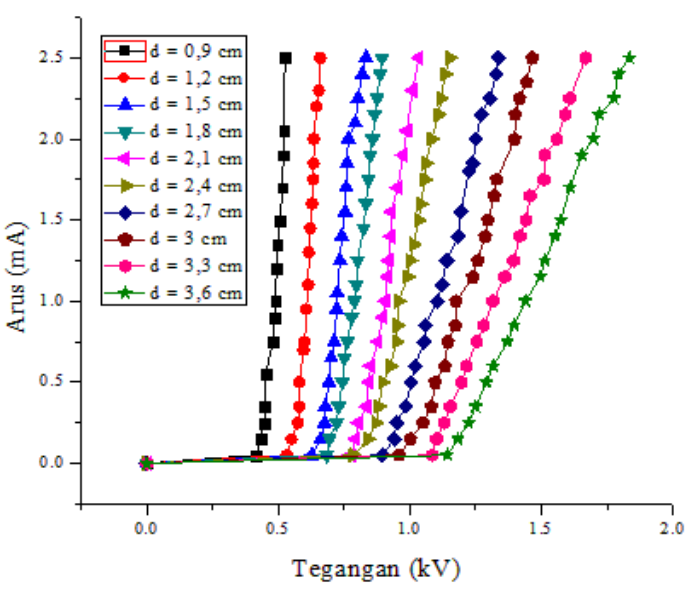

(a)

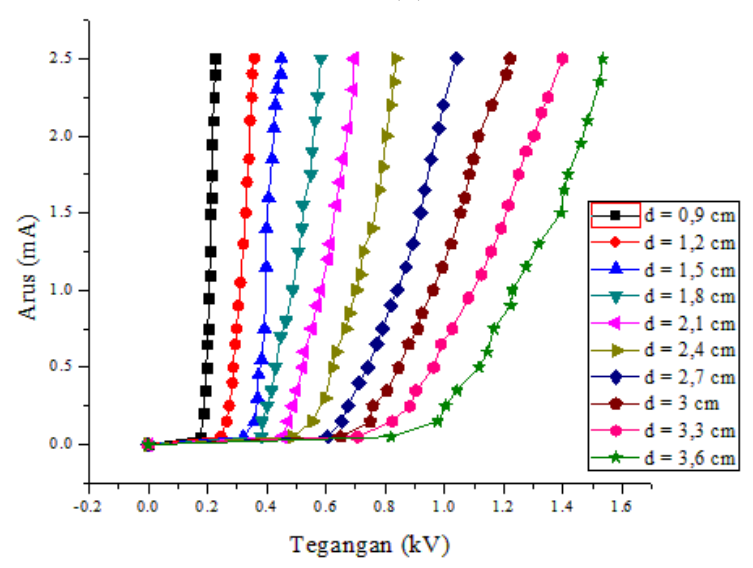

(b)

Gambar 2.(a) Karakterisasi arus (I) dan tegangan (V) tanpa sampel (b) Karakterisasi arus (I) dan tegangan (V) dengan sampel kain poliester grey.

Mobilitas Rerata Pembawa Muatan pada Reaktor Lucutan Plasma Korona

Mobilitas ion adalah kecepatan yang diperoleh suatu ion yang bergerak dalam ruang elektroda dalam setiap satuan medan listrik. Mobilitas pembawa muatan $(\mu)$ dipengaruhi oleh karakteristik arus dan tegangan I-V. ${ }^{5}$

Gambar 3 memperlihatkan bahwa nilai mobilitas menurun seiring dengan bertambahnya jarak elektroda, dan nilai mobilitas ion menggunakan sampel kain lebih besar dibandingkan tanpa sampel. Hal ini dikarenakan saat elektroda yang disisipi bahan dielektrik diberikan medan listrik, maka muatan-muatan didalamnya akan terpolarisasi. Muatan-muatan yang berada pada bahan dielektrik akan terbentuk dipol-dipol listrik dan tertarik menuju kutub yang berlawan pada elektroda, dimana muatan positif dari bahan dielektrik akan tertarik menuju katoda dan muatan negatif akan tertarik menuju anoda. Hal tersebut menyebabkan muatan keseluruhan meningkat dan terjadinya kenaikan arus pada hasil karakterisasi. ${ }^{8}$ Meningkatnya arus menyebabkan nilai mobilitas semakin membesar, karena pada dasarnya nilai mobilitas ion dipengaruhi dari hasil karakterisasi arus dan tegangannya.

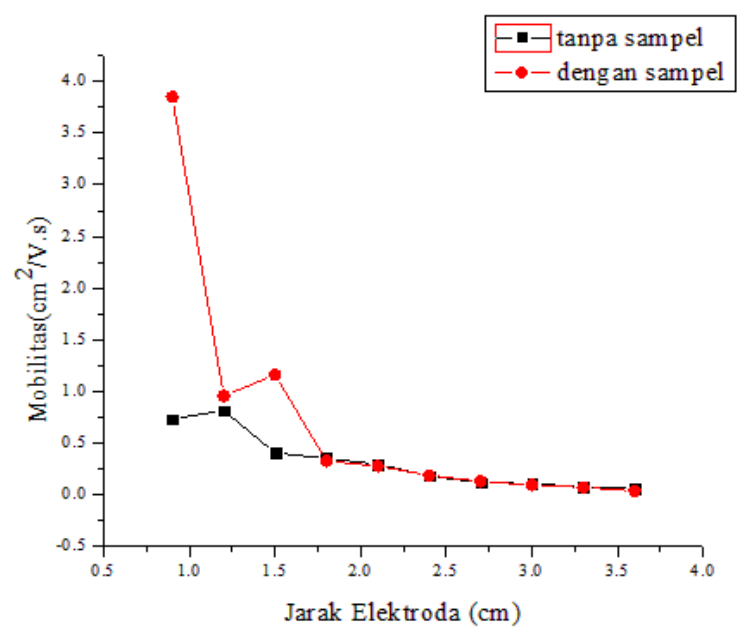

Gambar 3. Mobilitas rerata pembawa muatan reaktor plasma sebagai fungsi dari jarak elektroda.

Pada Gambar 3 hasil nilai mobilitas ion tanpa sampel diperoleh nilai mobilitas maksimum sebesar $0,813 \mathrm{~cm}^{2} /$ Vs pada jarak antar elektroda 1,2 $\mathrm{cm}$, sedangkan mobilitas minimum nya sebesar $0,062 \mathrm{~cm}^{2} / \mathrm{Vs}$ pada jarak antar elektroda $3,6 \mathrm{~cm}$. Mobilitas dengan sampel kain poliester grey diperoleh nilai mobilitas maksimum sebesar 3,852 $\mathrm{cm}^{2} / \mathrm{Vs}$ pada jarak antar elektroda $0,9 \mathrm{~cm}$ sedangkan mobilitas minimumnya sebesar 0,034 $\mathrm{cm}^{2} /$ Vs pada jarak antar elektroda $3,6 \mathrm{~cm}$. Nilai mobilitas yang didapatkan akan menurun seiring dengan bertambahnya jarak antar elektroda, tetapi terdapat ketidakstabilan lucutan pada reaktor plasma. Hal ini dapat dilihat dari hasil mobilitas yang meningkat yaitu jarak $1,2 \mathrm{~cm}$ pada mobilitas tanpa kain dan jarak 1,5 cm pada mobilitas dengan sampel kain. Hasil ini dipengaruhi oleh nilai mobilitas ionnya.

\section{Analisis Grafik Uji Tetes Cairan Sampel Kain Poliester grey}

Analisis uji tetes cairan diawali dengan proses peradiasian kain poliester grey dengan variabel proses, yaitu jarak elektroda dan lama waktu peradiasian. Pada penelitian ini jarak yang dilakukan yaitu pada $1,2 \mathrm{~cm}, 1,5 \mathrm{~cm}, 1,8 \mathrm{~cm}, 2,1$ $\mathrm{cm}$ dan $2,4 \mathrm{~cm}$, dengan variasi lama waktu peradiasian 0 menit, 5 menit, 10 menit, 15 menit, 20 menit, 25 menit, 30 menit, dan 35 menit. Iradiasi kain poliester grey dilakukan pada arus stabil yaitu 2,25 mA. Setelah dilakukan peradiasian, kain akan disimpan selama 24 jam sebagai waktu tunda, lalu dilakukan proses uji tetes cairan. Uji tetes cairan dilakukan menggunakan buret $25 \mathrm{ml}$ sebagai media penetesan air, lalu kain yang sudah diiradiasi dan disimpan selama 24 jam akan ditetesi air dan 
dihitung waktu serapnya, proses ini dilakukan pengulangan sebanyak 9 kali untuk mendapatkan hasil yang optimal. Uji tetes cairan ini bertujuan untuk mengetahui perubahan sifat fisis kain setelah diiradiasi dengan reaktor plasma berarus negatif dengan konfigurasi elektroda multi titik-bidang. Hasil uji tetes cairan digambarkan pada Grafik 4.

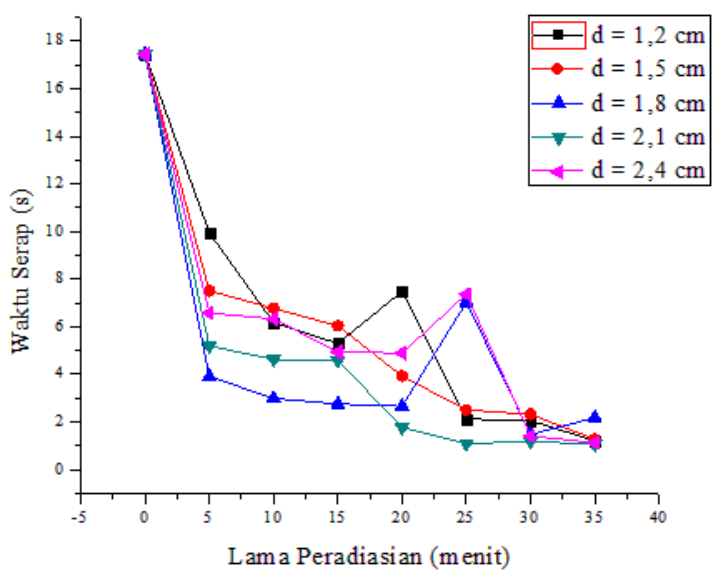

Gambar 4. Hasil uji tetes cairan sampel kain poliester grey dengan variasi jarak tertentu.

Berdasarkan Grafik 4 dapat disimpulkan bahwa semakin lama waktu peradiasian maka semakin cepat waktu serap kain poliester grey. Hal ini terjadi karena adanya interaksi antara plasma dengan permukaan kain poliester grey, dimana gas pada udara normal yang diberi energi sebesar tertentu akan tereksitasi hingga membentuk plasma yang terdiri atas gabungan ion, elektron, spesies tereksitasi dan radikal bebas dengan reaktivitas tinggi yang dapat berinteraksi baik secara fisika maupun kimia dengan permukaan substrat. ${ }^{9}$ Pada dasarnya perlakuan dengan plasma lucutan korona dapat menyebabkan permukaan kain mengalami oksidasi (membentuk gugus fungsional kimia baru) sehingga dapat memunculkan gugus-gugus polar seperti $-\mathrm{OH},-\mathrm{COOH},-\mathrm{CO}$ dan $-\mathrm{NH} 2$ pada lapisan permukaan kain. Gugus-gugus polar ini dapat meningkatkan sifat hidrofilik dan meningkatkan kecepatan pembasahan pada kain poliester grey. ${ }^{10}$ Namun jika tidak ditemukannya pembentukan gugus fungsional baru pada kain poliester grey setelah perlakuan plasma, maka peningkatan kecepatan pembasahan lebih mungkin diakibatkan oleh efek etsa (pengikisan) yang terjadi karena degradasi/kerusakan pada permukaan kain poliester grey. Plasma yang terbentuk selama proses perlakuan berlangsung dapat mengubah sebagian serat pada permukaan kain poliester grey menjadi gas sehingga permukaan serat seperti terkikis dan menimbulkan efek etsa. Efek etsa akan membentuk kekasaran pada permukaan kain poliester grey yang dapat memberikan ruang untuk ditempati oleh molekul-molekul air sehingga daya basah kain poliester grey meningkat. ${ }^{11}$

Hasil paling efektif memberikan perubahan sifat fisis pada kain yaitu pada jarak 2,1 cm dengan lama waktu peradiasian 35 menit, didapatkan ratarata waktu serap sebesar 1,06 detik berbanding jauh dengan rata-rata waktu serap pada kain sebagai kontrol yaitu 17,44 detik.

\section{KESIMPULAN}

Berdasarkan penelitian yang telah dilakukan dapat disimpulkan sebagai berikut :

1. Karakterisasi arus $(I)$ sebagai fungsi terhadap tegangan $(V)$ adalah semakin besar tegangan yang diberikan, maka semakin besar pula arus yang dihasilkan. Dapat dilihat saat diberikan tegangan $0,415 \mathrm{kV}$, arus yang dihasilkan sebesar $0,05 \mathrm{~mA}$, tetapi saat tegangan yang diberikan mencapai $0,525 \mathrm{kV}$, arus yang dihasilkan sebesar 2,5 mA. Peristiwa tersebut berlaku pada karakterisasi tanpa sampel maupun dengan sampel kain poliester grey.

2. Mobilitas ion yang didapatkan menunjukkan bahwa semakin besar jarak elektroda maka semakin kecil nilai mobilitas ion yang dihasilkan, dan nilai mobilitas ion dengan sampel kain poliester grey lebih besar dibandingkan tanpa sampel kain. Berdasarkan hasil juga terlihat ketidakstabilan lucutan yang menyebabkan nilai mobilitas ion naik pada jarak tertentu seperti terlihat pada jarak $1,2 \mathrm{~cm}$ pada karakterisasi tanpa sampel dan pada jarak 1,5 cm pada karakterisasi dengan sampel kain poliester grey.

3. Uji tetes cairan menunjukkan bahwa semakin lama waktu peradiasian maka semakin cepat waktu serap kain poliester grey. Hal ini berlaku pada semua jarak elektroda yang dilakukan saat iradiasi plasma pada kain. Berdasarkan data yang didapatkan, hasil yang paling efektif yaitu pada jarak 2,1 cm dengan lama peradiasian 35 menit, didapatkan rata-rata waktu serap sebesar 1,06 detik, sedangkan besar rata-rata waktu serap pada kain kontrol yaitu 17,44 detik.

\section{UCAPAN TERIMA KASIH}

Penulis mengucapkan terimakasih kepada Dr. Muhammad Nur, DEA, Ade Ika Susan, M.Si dan seluruh pihak di Central of Plasma Research (CPR) yang telah membuka jalan penelitian aplikasi plasma. Penulis juga mengucapkan terimakasih kepada seluruh pihak di laboratorium Fisika Atom dan Inti atas dukungan sarana dan prasarana selama proses penelitian.

\section{PUSTAKA}

1. Kailani, Z. A. Pemanfaatan Energi Plasma dalam Proses Tekstil untuk Memperbaiki SifatSifat Kain. Prosiding Seminar Nasional Sains dan Teknik Nuklir. 507-513 (2005). 
2. Ghoranneviss, M., et al. Decolorization of Denim Fabrics with Cold, Plasmas in The Presence of Magnetic Fields. Plasma Procesess and Polymers 3 (3), 316-321 (2006).

3. Nur, M. Fisika Plasma dan Aplikasinya. Semarang: Badan Penerbit Universitas Diponegoro. (2011).

4. Chang, J. S. Corona Discharge Processes, IEEE Transaction on Plasma Science 19 (6), 1152 1166 (1991).

5. Nur, M., Bonifaci, N., and Denat, A. Ionic Wind Phenomenon and Charge Carrier Mobility in Very High Density Argon Corona Discharge Plasma. Journal of Physics, Conference Series 495 (1), (2014).

6. Xu, W., and Xin, L. Surface Modification of Poliester grey Fabric by Corona Discharge Irradiation. European Polymer Journal 39, 199-202 (2003).

7. Triadyaksa, P., dkk. Rancang Bangun dan Pengujian Sistem Reaktor Plasma Lucutan Pijar Korona Guna Mempercepat Pertumbuhan
Tanaman Mangrove. Berkala Fisika 10 (3), 137-144 (2007).

8. Susan, A. I. Kajian Perubahan Sifat Pembasahan Kain Poliester grey dan Kapas Akibat Radiasi Plasma Lucutan Pijar Korona. Thesis magister Ilmu Fisika. UNDIP. (2016).

9. Chonqi, M., Shulin, Z., and Gu, H. Antistatic Charge Character of the Plasma Treated Poliester Filter Fabric. Journal of Electrostatics 68, 111-115 (2011).

10. Sjaifudin, A., dkk. Modifikasi Permukaan Bahan Tekstil dengan Plasma Lucutan Korona, Proceeding Indonesian Textile Conference Semnasteks 2014, 1-22 (2014).

11. Parvinzadeh, M., and Ebrahimi, I. Atmospheric air-plasma treatment of poliester fiber to improve the performance of nanoemulsion silicone. Applied Surface Science 257, 40624068 (2011). 